\title{
CAMPESINIDADE E TERRITÓRIO QUILOMBOLA NO NORTE DO ESPÍRITO SANTO ${ }^{1}$
}

\author{
Simone RAQuel Batista FerReIRA* \\ Projeto Territorial Quilombola (INCRA/UFES)
}

\section{Breve histórico}

O Extremo Norte do Espírito Santo configurava, até meados do século XX, um extenso território negro, inserido na densa floresta tropical e sapezais que circundavam as numerosas lagoas e rios. Estes agrupamentos originaram-se pela apropriação de terras no período escravocrata ou posterior, ora através de fugas, ora através da doação de antigos senhores e da Igreja. O território negro dava-se não pela propriedade, mas pela apropriação e uso comum destes recursos, através de práticas extrativistas nas grandes extensões de matas, brejos e rios, assim como da pequena produção das roças. A forma da organização produtiva, baseada na posse e uso comum, é definida por Alfredo Wagner B. de Almeida como sistema de uso comum:

Constituem-se, por outro lado, paradoxal e concomitantemente, em modalidades de apropriação da terra, que se desdobraram marginalmente ao sistema econômico dominante. Emergiram, enquanto artifício de autodefesa e busca de alternativa de diferentes segmentos camponeses, para assegurarem suas condições materiais de existência, em conjunturas

\footnotetext{
${ }^{1}$ O presente trabalho constitui desdobramento da Releitura Crítica de Projeto de Doutorado, realizada em 2005 junto ao Programa de Pós-Graduação em Geografia da Universidade Federal Fluminense. " Geógrafa (1995) e Mestre em Geografia Humana (2002) pela Universidade de São Paulo; doutoranda' do Programa de Pós-Graduação em Geografia da Universidade Federal Fluminense, sob orientação do Prof. Dr. Carlos Walter Porto Gonçalves. E-mail: sibatista@click21.com.br.
} 
de crise econômica também cognominadas pelos historiadores de "decadência econômica".[...] Em diferentes situações examinadas, conforme se verificará adiante, registra-se que este campesinato pósplantation não procedeu necessariamente a uma divisão da terra em parcelas individuais. A garantia da condição de produtores autônomos uma vez ausente o grande proprietário ou por demais debilitado o seu poder, conduziu a formas organizativas, sendo os ditames de uma cooperação ampliada e de formas de uso comum da terra e dos recursos hídricos e florestais. (ALMEIDA, 1989: 170-172)

Nesses sertões, a terra era à rola, assim como os demais recursos que supriam a existência. A terra à rola configurava a disponibilidade de terras, fator fundamental na organização destes grupos, e é atestada pelo depoimento de Dona Dorota, antiga moradora da Comunidade do Angelin:

De primero, minha filha, vou te contar, você chegava lá no Angelin, você fazia uma casa aqui... ai você ia embora, voltava de novo, tornava a fazer lá diante, assim que era, que era do Estado... A terra era a rola! (Dorotéia Batista, 77, em 04.05.99).

Referindo-se ao tipo social e cultural do universo das culturas tradicionais do homem do campo no Brasil, Antonio Cândido (1998) utiliza o termo rústico, que englobaria a cultura camponesa, cabocla ou caipira, definida pelas características da posse e disponibilidade de terras, relativo isolamento, trabalho doméstico, auxílio vicinal e margem de lazer. $\mathrm{O}$ conceito trabalha a questão organizacional das comunidades, ou seja, a forma como as comunidades se organizam coletivamente para garantir sua reprodução social.

A questão do isolamento necessita ser melhor analisada. Configurando o território como um todo e em suas redes de relações, os agrupamentos negros situavam-se ao longo dos vales de rios. Em algumas localidades, estes agrupamentos concentravam-se ao redor de capelas e campos de futebol, lugar do encontro, concretizando as relações de vizinhança mais próximas entre as famílias e constituindo-se em bairros rurais (QUEIROZ, 1973).

Da mesma maneira, sua inserção na sociedade mais abrangente se estabelecia principalmente em relação à cidade mais próxima, onde se efetivavam as trocas comerciais. Ainda povoa a memória dos mais antigos a época em que se levava alguns produtos da roça no lombo do animal para serem vendidos nas cidades de Conceição da Barra e São Mateus: abóbora, aipim, farinha de mândioca, lenha. Em algumas localidades, o trajeto até a cidade era realizado pelos rios, em canoas e botes, prática que ainda se observa atualmente entre moradores da beira do rio Cricaré, ao se deslocarem semanalmente para a feira na cidade de Conceição da Barra. Assim, a venda do excedente e portanto, a relação com o mercado, sempre esteve presente 
na vida deste campesinato, como busca de "alternativas econômicas que os integrassem positivamente à economia local e regional". (WANDERLEY, 1999:43)

Além das relações comerciais, as festividades religiosas muito presentes proporcionavam o encontro constante entre estes diversos agrupamentos, fosse na roça ou nos bairros rurais, fosse na cidade. Assim se homenageavam os santos, em festas entremeadas pelos cultos religiosos cristãos e pelas brincadeiras do Reis de Boi, Ticumbi e Jongo. No decorrer do ano anterior às festas religiosas concentradas nos meses de dezembro e janeiro, os ensaios das brincadeiras do Ticumbi e Reis de Boi ainda tomam lugar no meio rural, proporcionando também o encontro entre seus moradores.

Dessa maneira, faz-se necessário contextualizar a relativa situação de isolamento apresentada por Cândido (1998). Em suas relações internas, esses camponeses mantinham redes constantes de trocas materiais e simbólicas; externamente, mantinham relações pontuais e também constantes com os centros comerciais mais próximos. Com a decadência das grandes fazendas escravocratas, uma situação de relativo isolamento do Norte do Espírito Santo foi criada em relação à sociedade hegemônica, ao modo de vida urbano-industrial que se ampliava a partir da década de 1960 , inclusive no campo. Esta situação também fora possibilitada pelo quadro natural e as dificuldades que impunha a sua penetração, acompanhada da luta de grupos indígenas pela defesa de seu território: a densa floresta tropical úmida, entrecortada por numerosos e caudalosos rios e zonas de inundação, habitada sobretudo pelos grupos indígenas Aimorés. Tudo isso contribuiu para deixar o Norte do Espírito Santo em situação quase inatingível pelos grandes projetos de desenvolvimento até meados do século XX.

É a partir deste momento que as condições de vida deste campesinato negro passam a sofrer profundas alterações. O extermínio indígena, a construção da ponte sobre o rio Doce e mais tarde, a construção da BR-101, constituiram os vetores da nova penetração capitalista deste território. A floresta passa a ser valorizada pelo capital, para alimentar a construção civil dos centros urbanos de São Paulo e Rio de Janeiro do Pós-Guerra. (BECKER, 1973). Em momento contíguo, as zonas planas dos Tabuleiros Terciários ocupados pela floresta e pelo campesinato negro foram transformadas no território de expansão da monocultura de eucalipto para fins de produção de carvão vegetal (que já vinha sendo produzido com madeira da floresta pela ACESITA Energética), para alimentar fornos siderúrgicos) e de celulose.

Os grandes plantios de eucalipto para a produção de celulose no Brasil tiveram forte impulso através do Programa Nacional de Papel e Celulose, integrante do II PND - Plano Nacional de Desenvolvimento, elaborado pelo governo Geisel em 1974 e que tinha por meta a ampliação do consumo interno e da exportação de celulose e de papel. A chamada "Política Florestal" já se implantava desde a década de 1960 e primava por um planejamento estratégico da produção, através da criação de legislações específicas e normas fiscais de incentivo ao setor, bem como de 
órgãos oficiais de fomento e fiscalização dos plantios, como o IBDF - Instituto Brasileiro de Desenvolvimento Florestal, criado em 1967.

No mesmo ano da criação do IBDF, a ARACRUZ FLORESTAL inicia sua produção no município de Aracruz-ES, visando a exportação de cavacos para países produtores de celulose. Em 1972, é iniciada a construção da primeira fábrica da ARACRUZ CELULOSE, que passa a expandir seus plantios aos municípios de São Mateus e Conceição da Barra, visando a produção de celulose para exportação.

A escolha dessas duas localidades fora atribuída a alguns fatores favoráveis, como a topografia dos Tabuleiros Terciários, favorável à mecanização, a dinâmica climática e a proximidade do porto de Vitória, que facilitava a exportação - no caso do município de Aracruz. No entanto, o que se verifica é que ambas as localidades constituíam territórios étnicos que vinham sendo ocupados de forma ancestral, e não se legitimavam pela lógica da propriedade privada da terra-mercadoria, mas sim pela apropriação comum da terra como sustentação da vida. Sob o aval jurídico, esta situação facilitou a expropriação camponesa, através da derrubada da floresta e de mecanismos de coerção e ameaças que intimidavam os moradores locais, estimulando um intenso processo migratório para as cidades regionais e outros centros urbanos maiores, como a capital do estado.

O atual município de Aracruz era parte do território Tupinikin, que se estendia do sul da Bahia ao Paraná. A partir da década de 1960, passa também a ser território Guarani, povo que aí chega do sul do país em busca da "Terra Prometida" e é acolhido pelos Tupinikin. Quanto a São Mateus e Conceição da Barra, constituíam territórios de antigos agrupamentos negros rurais, oriundos dos "tempos da escravidão" guiados pelas fazendas de exploração de madeira e produção de farinha de mandioca. Assim, em ambos os territórios, a ausência de documentação de propriedade da terra facilitava a especulação imobiliária e a grilagem, consolidando o processo de territorialização do capital através da expropriação das comunidades.

Nessas localidades, a monocultura do eucalipto se estabeleceu no ambiente da Floresta Ombrófila Densa que ocupava os Tabuleiros. A destruição desta rica floresta através do machado, da moto-serra e do trator de esteira, o correntão - símbolo do desmatamento, significou a perda de uma riquíssima biodiversidade, que para essas comunidades locais significou também a perda do alimento - frutos e peixes e caças, a perda da água, a perda dos medicamentos, a perda da terra de uso comum - espaço utilizado com práticas de extrativismo vegetal, animal e pequena agricultura itinerante - para o uso do monopólio ditado pelo capital.

Para os que ficaram no território, a derrubada da floresta significou a perda do alimento, da água e demais recursos utilizados na reprodução de suas vidas. Em meio a inúmeras dificuldades de ali permanecer, os agrupamentos desse campesinato negro encontram-se hoje imprensados majoritariamente pela extensa monocultura de eucalipto da empresa Aracruz Celulose, seguida da cana-de-açúcar e das pastagens. A superposição de territórios se estabelece em meio a conflitos, que hoje se acirram diante da possibilidade da titulação destas terras como território quilombola. 


\section{Delimitando a opção teórica}

Discutir as possibilidades de utilização da teoria do campesinato na sociedade contemporânea implica efetuar a delimitação das questões que se quer enfocar, ou seja, a problemática que se quer analisar à luz de conceitos e categorias definidas. Em sua totalidade, a problemática levantada "testa" os referenciais teóricos, evidenciando, em alguns casos, sua eficácia no entendimento da realidade, e em outros, suas limitações. No dizer de Teodor Shanin:

Os conceitos são instrumentos de análise; sua utilidade e utilização estão sujeitas às perguntas feitas, às maneiras como estas se relacionam aos esquemas de questionamento teórico mais gerais e a seu esclarecimento da realidade.[...] Só a definição de uma problemática torna possivel a seleção de um quadro de referências conceitual válido. (SHANIN, 1980: 70-71)

Faz-se importante assinalar, também, que qualquer teoria deve estabelecer uma relação dialética com o que é concreto: as interpretações são realizadas neste diálogo entre o que é empírico e o que é elaboração, efetivando assim a construção teórica. Longe de se difundir a idéia de conceitos e categorias de abrangência universal, o recorte teórico e metodológico implica em escolhas que visam proporcionar maior profundidade na compreensão das questões apresentadas. As opções de quem investiga e pesquisa trazem em si sua visão social de mundo (LÖWY, 1992); tanto as questões levantadas como as respostas procuradas são gestadas neste universo de valores do sujeito pesquisador, inserido numa sociedade determinada.

No nosso caso, uma sociedade inserida no sistema capitalista, que se move através da acumulação de riquezas produzidas pela relação social da expropriação e produção do capital. Esta relação estabelece padrões de dominação de uns sobre outros, que é retro-alimentada ideologicamente pelas representações construídas. As representações constituem leituras acerca da realidade, que são transmitidas como "a realidade" em si. No processo de comunicação, algumas representações conseguem atingir o nível do que está dado e aceito. Numa sociedade conflitada por grupos dominantes e dominados, a disputa pelo estabelecimento de leituras do mundo social acontece paralelamente às demais lutas. No dizer de Pierre Bourdieu:

[...] la construction sociale de la realité sociale s'accomplit dans et par les innombrables actes de construction antagonistes que les agents opèrent, à chaque moment, dans leurs luttes individuelles ou collectives, spontanées ou organisées, pour imposer la représentation d'un monde social la plus conforme à leurs intérets [...] (BOURDIEU, 1977)

Esta disputa de caráter ideológico não acontece sobre as mesmas condições, entre ambos os sujeitos sociais. Sabe-se que os grupos dominantes assim o são não 
só devido à dominação econômica, mas sobretudo devido à superestrutura produzida para legitimar seu poder, engendrada num círculo de representações que tornam "natural" esta divisão social e obscurecem o processo histórico dos conflitos e as potencialidades de reação e resistência.

A escolha da temática territórios quilombolas no Norte do Espírito Santo traz embutida a questão do conflito social e das lutas, já incorporada em sua formulação conceitual. Em primeiro lugar, cabe analisar o conceito quilombola. Remetendo a uma história de lutas de uma população negra escravizada, o quilombo constituiu-se numa concretude de resistência territorial frente ao modelo econômico dominante. Ali, a mão-de-obra escrava das grandes fazendas monocultoras era re-transformada em grupos familiares que produziam sua existência material através de práticas agrícolas e extrativistas. Organizados num modo de vida peculiar, delimitado por fronteiras defendidas, estes quilombos constituíam territórios da liberdade, que se contrapunham ao sistema dominante, calcado nas relações escravistas que estruturavam as extensas unidades de produção comercial exportadora. Os territórios quilombolas aparecem, então, enquanto espaços apropriados por estes grupos humanos antes escravizados, num processo de ruptura em relação ao contexto predominante.

Entretanto, cabe ressaltar aqui que o termo quilombo vem passando por um processo de ressemantização, que caminha no sentido de ampliar a consideração de grupos como quilombolas, estendendo-se além da questão da ancestralidade africana. Assim, de acordo com o documento do Grupo de Trabalho da Associação Brasileira de Antropologia sobre Terra de Quilombo, de 1994:

[...] o termo quilombo tem assumido novos significados na literatura especializada e também para grupos, indivíduos e organizações. Ainda que tenha um conteúdo histórico, o mesmo vem sendo "ressemantizado" para designar a situação presente dos segmentos negros em diferentes regiões e contextos do Brasil.[...] consistem em grupos que desenvolveram práticas cotidianas de resistência na manutenção e reprodução de seus modos de vida característicos e na consolidação de um território próprio [...] No que diz respeito à territorialidade desses grupos, a ocupação da terra não é feita em termos de lotes individuais, predominando seu uso comum. A utilização dessas áreas obedece à sazonalização das atividades, sejam agricolas, extrativistas ou outras, caracterizando diferentes formas de uso e ocupação dos elementos essenciais ao ecossistema, que tomam por base laços de parentesco e vizinhança, assentados em relações de solidariedade e reciprocidade. (O'DWYER, 2002:18-19)

A luta pela conquista dos territórios quilombolas deve ser situada dentro de um quadro mais amplo do campesinato brasileiro, historicamente caracterizado pelas lutas pela conquista da terra: 
É preciso considerar, antes de tudo, que o modelo original do campesinato brasileiro reflete as particularidades dos processos sociais mais gerais, da própria história da agricultura brasileira, especialmente o seu quadro colonial, que se perpetuou como uma herança após a independência nacional; a dominação econômica, social e politica da grande propriedade; a marca da escravidão e a existência de uma enorme fronteira de terras livres ou passiveis de serem ocupadas pela simples ocupação e posse. [...] Assim, a história do campesinato no Brasil pode ser definida como o registro das lutas para conseguir um espaço próprio na economia e na sociedade.[...] refiro-me às lutas por um espaço produtivo, pela constituição do patrimônio familiar e pela estruturação do estabelecimento como um espaço de trabalho da família. (WANDERLEY, 1999: 39)

A terra, espaço de trabalho da família e patrimônio, carregada de valorizações simbólicas, é a base da constituição dos grupos camponeses. A escolha pela elaboração conceitual da campesinidade caminha no sentido de caracterizar internamente este grupo social como sujeito criando sua própria existência (CHAYANOV, [1925]1974), cujo trabalho na terra é destinado, primeiramente, à satisfação das necessidades da família e reprodução de sua vida. Na história agrária brasileira, a importância social do campesinato foi pouco reconhecida, muito embora fosse ele também responsável pela produção de alimentos para o mercado interno. Ao contrário, concretizando uma outra relação com a terra e com seus pares, este sujeito social muitas vezes significou o empecilho a ser removido pelos projetos e políticas de desenvolvimento, historicamente delineados pela grande produção agrícola monocultora e exportadora. Como os territórios quilombolas, este também foi o caso das Ligas Camponesas, que nas décadas de 1950/ 60 atuavam no questionamento da estrutura fundiária do Nordeste, altamente concentrada; ou o caso de Canudos, que messianicamente procurou construir o território livre na terra prometida.

A Lei de Terras de 1850, ao definir o acesso à terra somente através do processo de compra, procurava inviabilizar a apropriação camponesa do meio de produção, em especial do campesinato negro, que caminhava no sentido da abolição de sua escravatura. Assim, embora "livres", permaneceriam sem ter o direito de posse - e sem as condições de adquirir a terra por eles ocupada até então.

O processo de modernização brasileira se faz sem a incorporação deste campesinato. Neste sentido, é emblemático o período da ditadura militar, que engendra os planos nacionais de desenvolvimento, baseados no ideal do crescimento capitalista. Ao depor o presidente João Goulart, o Golpe Militar de 1964 coloca freios e passa a controlar algumas políticas reformistas que vinham tomando corpo em prol dos trabalhadores rurais, como a criação do Estatuto do Trabalhador Rural (1963) e da CONTAG (1963). 
Assim, sob o discurso do "desenvolvimento rural" e da implementação da Reforma Agrária, o Estatuto da Terra é criado (Lei 4.504 de 1964). O Estatuto da Terra afirmava que a política de desenvolvimento rural deveria estar em harmonia com a industrialização do país. Definindo como "função social da terra" a produtividade, este instrumento jurídico estabelece a classificação das propriedades rurais em Minifúndio, Empresa Rural, Latifúndio por Exploração e Latifúndio por Dimensão, diferenciados entre si pelo tamanho da terra e o tipo de exploração efetivada.

Esse recorte que se estabelece acerca da realidade agrária do país se faz a partir da lógica da propriedade e produtividade capitalista da terra, e em nenhum momento se considera outras possibilidades de apropriação e vínculos com a terra, como a camponesa. A Empresa Rural surge como o ideal da modernização agrícola (WANDERLEY, 2003), intrinsecamente relacionada aos padrões da Revolução Verde; quanto aos Latifúndios, poderiam se modernizar e se transformar em empresas rurais, e assim se desvencilhar da possibilidade da desapropriação. Interessante salientar que o discurso da desapropriação e Reforma Agrária serviu aos interesses de se colocar "panos quentes" nos conflitos sociais que tomavam presença no campo. Concretamente, o que se verificou foi o incentivo à colonização de algumas regiões por estas populações camponesas em conflito, e aqui merece destaque 0 deslocamento de camponeses sem terra do Nordeste para a Amazônia, onde seriam reserva de mão-de-obra aos Projetos Agropecuários e Agrominerais. (OLIVEIRA, 1991).

Esse período foi crucial para determinar o processo de modernização da agricultura brasileira, pois engendrou políticas e também representações a respeito do campo. Na lógica dominante construída, não há lugar para o campesinato, conforme salienta Wanderley:

Essa natureza estrutural do capitalismo agrário brasileiro, a meu ver, qualificou a própria modernização da agricultura - uma 'modernização sob o comando da terra'. Ela é, também, responsável, em grande parte, por determinar o 'lugar' social do campesinato na sociedade brasileira ao longo de sua história. Trata-se primeiramente de um lugar negado, não reconhecido. (WANDERLEY, 1996: 56)

Ao questionar o modelo de desenvolvimento hegemônico - pela posição política ou pelas práticas efetuadas na reprodução da vida, os camponeses devem ser eliminados. No nível das representações e sob a lógica dominante, o campesinato deve ser eliminado inclusive conceitualmente, uma vez que carrega em si outras possibilidades e o peso histórico da luta para estar e entrar na terra.

Neste lugar teórico se coloca a opção pelo conceito da campesinidade e do campesinato para o entendimento dos territórios quilombolas no Norte do Espírito Santo: em decorrência de seu peso histórico de luta por estar na terra, lugar de reprodução de sua existência material, afetiva e simbólica; uma luta contínua que marca toda sua existência e que ganha novo fôlego no momento atual. 


\section{Campesinidade, território e patrimônio}

Embora diverso em suas especificidades, o campesinato é enfocado pela produção teórica a partir de algumas características que o unificam, tornando-se, assim, específico dentro do quadro geral da(s) sociedade(s).

Assim, por exemplo, segundo Robert Redfield (1960), haveria padrões integrados de atitudes dominantes entre os diversos grupos sociails camponeses. Entre estas atitudes estaria a supremacia dos valores morais, religiosos e simbólicos sobre os valores econômicos no entorno da agricultura; a reverência perante a terra, que se afirma como valor, junto ao trabalho familiar; a transmissão dos saberes às novas gerações (em especial, no tocante à reprodução da existência).

Teodor Shanin (1980), por sua vez, na tentativa de "testar" o conceito camponês, parte para sua desconstrução e elenca características que afirmariam sua generalidade/especificidade, como uma economia caracterizada por formas extensivas de trabalho familiar autônomo e controle dos próprios meios de produção; padrões específicos de organização política e de socialização; sistemas cognitivos próprios (como a percepção circular do tempo, estreitamente vinculada ao calendário produtivo) e costumes de herança.

Observa-se, pois, que as considerações destes dois autores a respeito dos conceitos camponês e campesinato já apresentam, em si, diferenças e semelhanças. A tentativa de objetivar um conceito que reúna as características de determinado sujeito social parece delicada, uma vez que este sujeito é histórico, e como tal, encontra-se em movimento e carrega contradições e ambigüidades, conforme a construção de Klaas Woortmann. A partir desta reflexão, o autor opta pelo uso do conceito campesinidade e assim desloca a discussão da caracterização objetiva do sujeito social para o entendimento de uma qualidade que estaria presente em suas práticas cotidianas, em maior ou menor grau:

Prefiro então falar não de camponeses, mas de campesinidade entendida como uma qualidade presente em maior ou menor grau em distintos grupos especificos. Se há uma relação entre formas históricas de produção e essa qualidade, tal relação não é, contudo, mecânica. O que tenho em vista é uma configuração modelar, mas é preciso não esquecer, sob risco de reificação, que pequenos produtores concretos não são tipos, mas sujeitos históricos e que as situações empíricas observadas, por serem históricas, são ambíguas. [...] Modelos nunca são 'iguais à realidade', se por essa última se entende a concretude histórica que é, essencialmente, movimento. (WOORTMANN, K., 1990:13)

Nesse sentido, propõe-se considerar não a investigação de critérios que atestariam a existência do "objeto" camponês, mas da qualidade oriunda de uma visão de mundo particular e presente nas práticas cotidianas de produção e 
reprodução da própria existência material, afetiva e simbólica, ou seja, do seu modo de vida. Esta existência não se dá de forma "ideal" e isolada, mas está inserida no contexto da sociedade global e globalizada, guiada, desde muito, pelos princípios do capital. Assim sendo, faz-se necessário considerar que a afirmação da campesinidade se dá por meio da elaboração de estratégias, que estabelecem o "jogo" com a sociedade da mercadoria. Sua concretude será construída com nuances e diferenças, oriundas desta relação.

No entender de Woortmann, esta instabilidade estaria produzindo possibilidades diferenciadas de campesinidade praticada. $\mathrm{Na}$ construção da campesinidade, algumas categorias culturais seriam comuns e inter-relacionadas, como terra, familia, trabalho e liberdade, definidoras de uma ordem moral presente nas sociedades camponesas. Segundo o autor, a estas categorias empíricas estariam associadas outras categorias antropológicas, relacionadas a valores e princípios organizatórios e ao sentido mais geral da humanidade: a reciprocidade, a honra e a hierarquia. Assim, nos dizeres de Woortmann:

Pensar trabalho é pensar terra e família; [...] Não são pensadas separadamente porque são categorias de um universo concebido holisticamente. Por outro lado, [...] honra, reciprocidade e hierarquia também não se pensam separadamente; são conceitos teóricos que se interpenetram na constituição da ordem moral que chamo campesinidade. (WOORTMANN, K, 1990:63)

A reciprocidade é a condição na qual se estabelecem as relações sociais camponesas. Define o aspecto da relação entre "iguais", constituindo um espaço de identidade e, ao mesmo tempo, de alteridade na relação com o outro, o "estranho".

O sistema de parentesco é valor social construído culturalmente e que organiza o trabalho e define a herança, permeando todas as práticas de produção e reprodução do campesinato. É em torno da família que giram as preocupações e tomada de decisões; e é em torno da família (nuclear, extensa ou "ancestral") que se estabelecem as relações de reciprocidade.

O trabalho da familia sobre a terra é o elemento central da lógica camponesa. A realização do trabalho na terra, comandada pelo pai, concretiza a reprodução da família, e por outro lado, reafirma a ordem hierárquica ditada pela autoridade do pai. Assim, a terra trabalhada recebe uma valoração baseada no uso e apropriação efetivada pela família através de seu trabalho e afirma a família enquanto valor. A terra trabalhada pela família constitui seu patrimônio:

Neste plano, por exemplo, o conceito de valor-de-uso ganha um outro valor: $o$ de uso enquanto valor. [...] Nessa perspectiva, não se vê a terra como objeto de trabalho, mas como expressão de uma moralidade; não em sua exterioridade como fator de produção, mas como algo pensado $e$ 
representado no contexto de valorações éticas. Vê-se a terra, não como natureza sobre a qual se projeta o trabalho de um grupo doméstico, mas como patrimônio da família, sobre a qual se faz o trabalho que constrói a família enquanto valor. Como patrimônio, ou como dádiva de Deus, a terra não é simples coisa ou mercadoria. Estou tratando, pois, de valores sociais; não do valor-trabalho, mas do trabalho enquanto valor ético. (WOORTMANN, K., 1990:12)

No caso das comunidades quilombolas, as famílias de hoje constituem a representação da ancestralidade africana, ou da "grande família original" em seu território. A ascendência comum afirma os traços da identidade quilombola criada por estes grupos e garante o direito ao território. Por meio do trabalho na terra, a ancestralidade quilombola imprimiu suas marcas e produziu o território-patrimônio, que deve ser transmitido às novas gerações, reafirmando a memória do grupo. Aqui pode-se perceber a importância da memória na afirmação do território, através da elucidação das redes de parentesco ascendentes e descendentes, como nos traz Ellen Woortmann:

Pode haver um pequeno número de gerações presentes no grupo local, o que, afinal, sempre acontece, por razões demográficas; mas a memória de parentesco pode ser longa, alcançando várias gerações ascendentes, como critério de reconhecimento de parentesco. (WOORTMANN, E., 1995:59)

A memória de parentesco constitui elemento característico da campesinidade e afirma o território quilombola. Concretizando traços de campesinidade, o território quilombola unifica as categorias de espaço e parentesco. No entanto, em virtude do contexto histórico de maiores ou menores conflitos com a sociedade abrangente, a manifestação da campesinidade quilombola pode se dar com intensidades diferenciadas, assim como suas práticas de territorialidade, que compreendem ações de afirmação do território enquanto espaço apropriado pelo grupo para a reprodução material e simbólica da sua existência.

Historicamente inserido em contextos conflituosos, o território quilombola concretiza a disputa entre sujeitos sociais e valores. Tem-se aqui a concepção do território na sua dimensão política, enquanto espaço onde se exerce um determinado poder. Por outro lado, o território quilombola apresenta sua dimensão cultural, relacionada ao espaço vivido e concebido pelo grupo. $\mathrm{E}$, no tocante à reprodução material da família a partir do trabalho na terra, sua dimensão econômica ganha relevância, enquanto fonte de recursos. Ao desenvolver uma reflexão sobre território, territorialidade e territorialização, Rogério Haesbaert elenca estas concepções:

Em nossa síntese das várias noções de território [...], agrupamos estas concepções em três vertentes básicas: 
- política (referida às relações espaço-poder em geral) ou jurídico-politica (relativa também a todas as relações espaço-poder institucionalizadas): a mais difundida, onde o território é visto como um espaço delimitado e controlado, através do qual se exerce um determinado poder, na maioria das vezes - mas não exclusivamente - relacionado ao poder político do Estado;

- cultural (muitas vezes culturalista) ou simbólico-cultural: prioriza a dimensão simbólica e mais subjetiva, em que o território é visto, sobretudo, como o produto da apropriação/valorização simbólica de um grupo em relação ao seu espaço vivido;

- econômica (muitas vezes economicista): menos difundida, enfatiza a dimensão espacial das relações econômicas, o território como fonte de recursos elou incorporado no embate entre classes sociais e na relação capital-trabalho, como produto da divisão 'territorial' do trabalho, por exemplo.

Posteriormente, acrescentamos ainda uma interpretação natural(ista), mais antiga e pouco veiculada hoje nas Ciências Sociais, que se utiliza de uma noção de território com base nas relações entre sociedade e natureza [...].(HAESBAERT, 2004:40)

No entanto, entende-se que as dimensões política, cultural e econômica do território quilombola estão interligadas e têm como base material as relações do grupo com a natureza, estabelecidas na construção de saberes próprios.

\section{Práticas produtivas: saberes na apropriação da natureza e presença no(do) mercado}

As práticas produtivas da existência camponesa revelam saberes nascidos da relação de apropriação da natureza. Esta relação de apropriação se estabelece permeada pelo sentido moral, onde a natureza e a terra aparecem como dádiva divina, e proporcionam a construção da morada da vida através do trabalho familiar:

Familia, trabalho e terra, nessa ordem social, constituem um ordenamento moral do mundo onde a terra, mais que coisa, é patrimônio, isto é, pessoa moral. De um lado, a relação do homem com a terra é uma relação de troca reciproca, onde o trabalho fecunda a terra que se torna morada da vida. A relação com a terra é uma relação moral com a natureza. (WOORTMANN, K. 1990:62) 
Segundo Antonio Cândido, a alimentação constitui um recurso vital que revela a dependência do grupo em relação ao meio e suas ações para garantir essa continuidade, bem como a organização social para obtê-la e distribuí-la. Assim, o calendário produtivo de uma comunidade camponesa apresenta-se como:

o centro de um dos mais vastos complexos culturais, abrangendo atos, normas, símbolos, representações. A obtenção da comida percorre, do esforço fisico ao rito, uma gama vastíssima em que alguns têm querido buscar a gênese de quase todas as instituições sociais. (CÂNDIDO, 1988:29)

A produção do alimento se estabelece, então, como relação moral dos homens com a natureza, onde a terra de trabalho é construída pelos saberes. A organização desta produção camponesa leva em conta o pulsar próprio da natureza, a partir do qual se constroem as técnicas mais adequadas e os processos de trabalho. Em suas práticas produtivas, as comunidades quilombolas expressam sua leitura do ambiente, desenvolvida num movimento de relações empíricas e cotidianas com o meio, na construção de seu modo de vida. A leitura que fazem do seu espaço ecológico nos remete aos usos que elas aí praticam, diretamente relacionados à reprodução da sua vida material e simbólica:

Factores tales como los componentes edáficos del suelo, la temperatura, la luminosidad, la humedad, la orografía y un largo etcétera constituyen elementos condicionantes que suponen posibilidades y limitaciones para los grupos humanos que habitan un medio determinado. Estos condicionamientos son, generalmente, conocidos por las gentes de un determinado lugar y en función de ese conocimiento actúan. (CONTRERAS, 1991:344)

No entanto, as comunidades quilombolas do Norte do Espírito Santo encontramse numa situação de grandes dificuldades de reprodução, decorrente da expropriação de terras e degradação das condições socio-ambientais provocadas pela monocultura do eucalipto para a produção de celulose. Verifica-se, desta forma, a perda de práticas e saberes que outrora estiveram estreitamente vinculados a uma relação moral com a natureza. As lideranças da Comunidade de Linharinho (situada no município de Conceição da Barra) preocupam-se com este processo em curso e o futuro das novas gerações, como salienta Vermindo dos Santos, 37, presidente da Associação dos Pequenos Produtores Rurais:

A preocupação minha como Presidente dos Pequenos Agricultores do Linharinho é sobre o território. O território é bom para fazer algum trabalho em renda prá subsistência da nossa comunidade, né?! Porque hoje, né, a 
gente se encontra dentro da nossa comunidade, é, às vezes tem 4, 5, 6, famílias morando dentro da terra e cê vai lá só tem 5 hectares, 7 hectares de terra. Então, antigamente, não tem espaço prá você é.. plantar e nem criar o seu porco, que não tem mais espaço, suas galinha, como o porco. Tinha espaço do território. Então o povo quilombola tinha nos antepassados, não tinha grande roça, mas eles tinha seu território que eles podia viver da sua caça, da sua pesca e, hoje, na chegada da Aracruz Celulose ... não tinha aquela grande quantidade de roça. Eles tinha sim, a sua roça pequena, mas fazia sua farinha, tinha seu feijãozinho pequeno, pra criar seus filhos. E hoje, nossa preocupação, que é a gente vai tendo filho, né, hoje os filho tão crescendo, e nóis não tamo querendo que eles sai das terra pra ir pra grande cidade. Que o que a gente vê, né, dentro da cidade, é fome, desemprego. Então, acho que não é só, se eles sair daqui pra voltar pra cidade, não vai resolver nosso problema. Vai continuar ficando na favela, desempregado... Que a cultura deles é uma, então, através da chegada da grande firma, acabou a cultura. Hoje, ninguém caça, não pesca, num tem uma área de terra apropriada pros animais. Ninguém tem mais os animais, que era o meio de transporte. Então, a nossa preocupação hoje é pensar das crianças que vão chegando, e nossos filhos, aonde vão morar? Aonde vão ficar? Vão pra cidade? Vão pra favela? Pra virar assaltante? Porque, se eles ir pra cidade, nóis não vamo encontrar serviço pra esse tanto de pessoa. Pra gente vê que não tem trabalho pra esse tanto de gente nas capital. (entrevista realizada por Simone Batista Ferreira com Vermindo dos Santos, 37, Comunidade Quilombola de Linharinho, dezembro/ 2004)

Ao enfocar as práticas produtivas desta comunidade, pode-se perceber a dimensão e intensidade da expropriação sofrida - da terra e sua fertilidade, da água e da floresta, que forçam por inviabilizar sua reprodução. A perda do ritmo cíclico da natureza altera o diálogo desta com a comunidade, refletindo no enfraquecimento dos saberes relacionados a esta dinâmica. A terra da floresta tropical não consegue mais falar com o agricultor e os problemas que apresenta muitas vezes inviabiliza a interação. Muito da diversidade produtiva se perdeu, como é o caso das sementes e plantas crioulas, nativas, de feijões, mandiocas e milhos, além das espécies de uso medicinal. No entanto, através do manejo agrícola, conseguiu-se manter alguma diversidade, vinculada a práticas e saberes e organizadas num calendário produtivo, como é o caso da mandioca e suas variedades.

Ainda há uma variedade de mandiocas (Manioc utilissima $s p$.) cultivadas e que podem ser plantadas o ano todo, sendo colhidas no prazo em torno de um ano. Algumas espécies antigamente cultivadas podiam ficar mais tempo na terra, "guardadas", enquanto que atualmente opta-se pelas espécies mais rápidas. Esta 
escolha parece revelar a escassez de terras para os cultivos, quando uma mesma terra tem que ser utilizada constantemente, sem descanso. Assim, os plantios devem produzir rápido e, via de regra, numa terra já "cansada" e "fraca". As chuvas definem o melhor momento para a colheita, uma vez que tornam a terra mais macia e friável para o arranque da raiz. Assim como demarca o período da colheita da mandioca, as chuvas iniciam o período de se fazer a farinha, na seqüência da colheita.

Esta produção possibilita a inserção camponesa no mercado, enquanto espaço de trocas complementares que visam a reprodução da família. Embora realize o valor monetário do trabalho familiar, a inserção no mercado por meio da venda da própria produção não significa, necessariamente, um espaço de reciprocidade, uma vez que o entendimento camponês de negócio é aquele da relação desigual, onde um sai ganhando e o outro perdendo e, assim, nega a moralidade:

Com parente não se neguceia, porque no negócio sempre um sai ganhando e outro sai perdendo.' Muitos sitiantes são também negociantes, mas o negócio é percebido como a negação da moralidade, pois ele significa ganhar às custas do trabalho alheio. É percebido, então, em oposição ao trabalho e como uma atividade que não envolve honra.(...)

Vender a própria produção e realizar o valor monetário do trabalho é expressão da autonomia camponesa. Neste sentido, a feira é um espaço de realização do pai de familia, que no roçado encarna o trabalho familiar e na feira 'governa' a transformação desse trabalho em ganho, necessário para 'botar de um tudo dentro de casa' (...).

Mas, a feira não é apenas o lugar de 'fazer a feira'. É, sobretudo, o espaço do negócio, um espaço não controlado pelo camponês; isso no plano das representações, pois, concretamente, muitos negociantes são também lavradores. Enquanto espaço de negócio, a feira se opõe à campesinidade. Por isso, ela se realiza na cidade - na rua - ou no engenho, sempre fora do território camponês. (WOORTMANN, K., 1990:38-39)

Por outro lado, muitas vezes o negócio é o que possibilita o acesso à terra e, portanto, a conquista da liberdade da família. Cabe analisar, então, em que condições se engendra o negócio em comunidades quilombolas, a fim de se avaliar uma maior ou menor proximidade da campesinidade.

Em relação à produção da farinha de mandioca, sempre se constituiu num produto de consumo doméstico e de troca comercial para as comunidades quilombolas do norte do Espírito Santo, materializando, então, a característica da alternatividade (GARCIA Jr., 1983), ou seja, tendo seu valor de uso para a comunidade e, ao mesmo tempo, o valor de troca no mercado, que é atribuído pelo valor de uso que representa ao comprador. Neste sentido, se o preço não está bom, o produto é absorvido pelo consumo familiar. 
Na produção da farinha, as relações familiares ocorrem desde o plantio, passando pela colheita da mandioca e o processo de fabrico nas casas ou cozinhas de farinha. Principalmente no momento de produzir a farinha, todo o trabalho é familiar, desde o processo de ralar a mandioca, prensar, tirar a goma - que será utilizada na produção do beiju e cozinhar a massa. Nas etapas de colheita, principalmente, há combinações entre quem cultivou e quem colhe, que envolvem meação e outras porcentagens sobre o produto final, ou ainda, o pagamento de diárias.

Algo semelhante acontece na utilização da "farinheira da Miúda", localizada na Comunidade de Linharinho, estrutura semi-industrial, totalmente mecanizada e que é utilizada na produção em escala comercial e para o uso doméstico. As outras famílias que dela se utilizam contribuem com o pagamento da energia elétrica. Se a farinha produzida é para a venda, tiram $20 \%$ do ganho e repassam aos donos da farinheira. Este mecanismo se aproxima do descrito por Garcia Jr.:

Nem toda unidade doméstica é proprietária de uma casa de farinha. Mas há sempre unidades domésticas, de pequenos proprietários, tendo casas de farinha entre os parentes elou vizinhos de uma determinada unidade doméstica. Ou seja: toda unidade doméstica tem sempre acesso a alguma casa de farinha, em que pode transformar a mandioca que cultivou. Quando não se é proprietário da casa de farinha, o acesso a esta depende da combinação com o chefe das unidades domésticas quem pertence. (GARCIA Jr. 1983:129-130)

Outros produtos vêm ganhando o espaço do mercado para as comunidades quilombolas do norte do estado, produzidos a partir da coleta dos galhos de eucalipto não utilizados para a produção de celulose - o facho. Um deles é o carvão vegetal, que alimenta as siderurgias do estado; o outro é a própria lenha, vendida para olarias do norte fluminense.

O negócio do carvão acontece dentro do sítio, quase no quintal, onde se encontram os fornos, lugar onde são feitas as transações de preço e a troca da mercadoria por dinheiro, que materializa o ganho quilombola através de seu trabalho. A venda do carvão é feita com o outro, o estranho, embora o negócio aconteça dentro do espaço mais íntimo do território, que é o espaço da morada. A lenha é comercializada na área do corte de eucalipto, depois de ser colhida e "baldeada" por tratores até os caminhões atravessadores.

Segundo Ariovaldo Umbelino de Oliveira, nos processos contraditórios do desenvolvimento capitalista no campo, o capital ora se territorializa sob a forma monopolista, ora monopoliza o território. Quando o capital se territorializa,

ele varre do campo os trabalhadores, concentrando-os nas cidades, quer para serem trabalhadores da indústria, comércio ou serviços, quer para 
serem trabalhadores assalariados no campo (bóias-frias). Nesse caso o processo especificamente capitalista se instala, a reprodução ampliada do capital desenvolve-se em sua plenitude. [...] A monocultura se implanta e define / caracteriza o campo, transformando a terra num 'mar' de cana, de soja, de laranja, de pastagem, etc. (OLIVEIRA, 1999:106)

Este é o caso das terras de propriedade privada da empresa Aracruz Celulose, que embora adquiridas sob mecanismos fraudulentos, concretizam as bases da maior produção mundial de celulose a partir do eucalipto. Quanto ao facho realizado pelas famílias quilombolas, o capital monopoliza o território e

cria, recria, redefine relações de produção camponesa, portanto familiar. Ele abre espaço para que a produção camponesa se desenvolva e com ela o campesinato como classe social. [...] o próprio capital cria as condições para que os camponeses produzam matérias-primas para as indústrias capitalistas ou mesmo viabilizem o consumo dos produtos industriais no campo. (OLIVEIRA, 1999:106)

Atualmente, estas atividades produtivas configuram-se como principal estratégia dos quilombolas para se manter na terra-patrimônio-território. Neste sentido, é afirmação da liberdade. No entanto, ao se analisar a questão da autonomia produtiva, é sujeição, nos dizeres de Woortmann, K.:

A liberdade do sitiante, do agricultor, do colono [...] tem como uma de suas dimensões a autonomia do processo de trabalho e do saber que a este informa, transmitido de pai a filho. A transmissão da terra sem o saber não transformaria essa terra em terra de trabalho, nem em patrimônio familiar. [...] A autonomia tem ainda outra dimensão: o controle do tempo. [...] Quem vive do alugado tem uma temporalidade distinta daquela do ciclo agricola e, por isso mesmo, não é agricultor. [...] não realiza subjetivamente o trabalho enquanto um valor cultural. Na medida em que não dirige o tempo da família, ele é sujeito. (WOORTMANN, K., 1990:43)

Ao contrário das relações de produção da farinha, nesta produção os quilombolas não possuem autonomia, pois dependem da liberação da matéria-prima definida pela empresa, de acordo com o tempo da grande produção de celulose. É este tempo que define o momento do corte do eucalipto e, em decorrência, o momento da atividade do facho, que deve ser dividido entre várias comunidades locais - e, portanto, está sempre na situação de não suprir todas as demandas.

No mesmo sentido, na venda do carvão ou da lenha, o preço é colocado pelo comprador, atravessador que transporta a mercadoria até as siderurgias ou olarias. 
Ou seja, na realização do valor monetário do trabalho, que o transforma em ganho, não há autonomia nem liberdade. $O$ tempo de trabalho é definido pela empresa produtora de celulose e a realização do valor-trabalho é definida pelas empresas consumidoras. Entretanto, na visão de Wanderley:

(...) mesmo nas sociedades rurais tradicionais, a autonomia é sempre relativa. A necessidade de reservar parte de seus recursos para as trocas com o conjunto da sociedade e para atender a suas imposições termina por introduzir no interior do próprio modo de funcionamento do campesinato certos elementos que the são, originalmente, externos. (WANDERLEY, 1999:30)

O uso do resíduo de eucalipto é resultante de uma conquista baseada na incorporação da identidade do território-patrimônio e implica numa relativa reapropriação do espaço, uma re-territorialização e uma territorialidade. Em primeiro lugar, porque se constrói sobre a afirmativa de um direito das comunidades sobre o território, que é ancestral e patrimônio. E, em seguida, porque através do facho, os descendentes dos ancestrais comuns conquistam a "autorização vigiada" para transitar pelo território também empresarial e redescobrem os lugares de morada dos véios e demais espaços que eram utilizados pelo trabalho na reprodução da existência, como lagoas e rios. Sob este aspecto, a atividade do facho tem um caráter ameaçador, fato que se revela na pretensão de absoluto controle da empresa sobre ele. Neste sentido se deu a obrigatoriedade da criação da Associação de Pequenos Agricultores e Lenhadores de Conceição da Barra - APAL/CB, condição imposta pela empresa Aracruz Celulose S.A. para o estabelecimento desta atividade, de modo a identificar e ter o controle de quem está transitando pelas áreas de corte, o território do capital.

Neste contexto, cabe discutir as possibilidades de liberdade e/ou sujeição que se apresentam a essas comunidades quilombolas, em vista de adquirirem juridicamente seus territórios patrimoniais. A territorialidade quilombola, projeção da identidade do grupo sobre o território e práxis que atua na afirmação cotidiana deste espaço apropriado, apresenta-se como possibilidade de questionamento concreto ao capital. No entanto, cabe o questionamento: no território demarcado, haverá liberdade ou um cativeiro recriado?

\section{A invenção do "território quilombola" e seu vir a ser}

A visibilidade do território quilombola no Norte do Espírito Santo vem se afirmando a partir de meados de 2002, quando uma primeira pesquisa, denominada Territórios Negros no Sapê do Norte, foi realizada pelas entidades Koinonia Presença Ecumênica e Serviço e FASE -Federação de Órgãos de Assistência 
Social e Educacional ${ }^{2}$. Este levantamento inicial resultou num banco de dados preliminar a respeito da ancestralidade e da situação atual destes grupos. Até então, a categoria quilombo não compunha o aparato das representações coletivas que estes grupos construíam em relação a si próprios e a seu território expropriado; iniciou-se como uma identidade atribuída, caminhando para uma identidade incorporada.

As indagações a respeito de seu tempo de vida naquele lugar trazia à tona o referencial da ancestralidade negra. Assim, as afirmações muito escutadas "ah, sou nascido e criado aqui, meus pais eram daqui, meus avós também", ou ainda "minha avó veio da África, falava enrolado", passavam a legitimar o direito à terra perdida, garantido pelo Artigo 68 da Constituição Federal:

Aos remanescentes das comunidades dos quilombos que estejam -ocupando suas terras é reconhecida a propriedade definitiva, devendo o-Estado emitir-lhes os títulos respectivos. (Artigo 68 - ADCT da Constituição Federal da República Brasileira, 1988)

Embora o Movimento Consciência Negra já atuasse na região há cerca de 20 anos, o sentido do território quilombola passa a nascer coletivamente a partir deste momento e, no município de Conceição da Barra, culmina na criação da Associação Quilombola, no ano de 2003. O resgate memorial das relações de parentesco entre os diversos agrupamentos nucleados, bem como entre eles e várias famílias situadas no meio urbano, colocam em evidência a dimensão deste território quilombola.

Embora tenha sido um primeiro avanço na consideração da questão, a referência do Artigo 68 a remanescentes das comunidade dos quilombos abre a discussão acerca do caráter de "quase extinção" dos mesmos, assim como o significado do coletivo perde importância, uma vez que podem ser interpretados no nível individual, e não da comunidade ancestral. Ademais, a temática é inserida nas Disposições Transitórias e o Artigo 68 fica sem homologação. Neste sentido, sua elaboração trouxe poucos avanços práticos relacionado à questão. Para ter a propriedade reconhecida das terras, o caráter quilombola da comunidade deveria ser atestado "cientificamente" através de laudos antropológicos, que, à luz do direito positivo, carregariam um maior sentido de "verdade" do que o apresentado pela vivência empírica destes grupos.

\footnotetext{
${ }^{2}$ Esta pesquisa foi realizada nos municípios de São Mateus e Conceição da Barra, entre maio de 2002 e fevereiro de 2003. Nela, desenvolvi parte do trabalho de coordenação, que consistia no planejamento do campo, no acompanhamento do trabalho dos jovens pesquisadores oriundos de famílias de origem quilombola da região, na identificação das lideranças e no mapeamento das comunidades através de croquis, situando as moradias e respectivos chefes de família, estruturas e outras informações relevantes.
} 
Um avanço significativo na questão veio com a elaboração do Decreto Presidencial n. ${ }^{\circ} 4.887$ de 20 de novembro de 2003, ao definir a auto-atribuição como o critério para o reconhecimento das comunidades quilombolas. Esta consideração afirma que a identidade do grupo sobre seu território-patrimônio é a condição maior para o impulsionamento do processo de conquista jurídica das terras:

Art. 2. ${ }^{\circ}$ Consideram-se remanescentes dâs comunidades dos quilombos, para os fins deste Decreto, os grupos étnico-raciais, segundo critérios de auto-atribuição, com trajetória histórica própria, dotados de relações territoriais especificas, com presunção de ancestralidade negra relacionada com a resistência à opressão histórica sofrida.

$\S 1 .^{\circ}$ Para os fins deste Decreto, a caracterização dos remanescentes das comunidades dos quilombos será atestada mediante autodefinição da própria comunidade. (Decreto $\mathrm{n}^{\circ} 4.887$, de 20 de novembro de 2003)

Ainda baseando-se na consideração de remanescentes das comunidades dos quilombos, o Decreto-Lei 4.887 passa a referir-se à questão da auto-atribuição do grupo como remanescente de quilombo. Com base na Convenção 169 da OIT Organização Internacional do Trabalho, a auto-atribuição passa a constituir a "prova" desta ancestralidade, embora contraditoriamente deva ainda ser certificada pela Fundação Palmares através de um cadastro do reconhecimento da comunidade enquanto quilombola. Por outro lado, a auto-atribuição está presente na definição e demarcação do território através da consideração dos critérios de territorialidade indicados pelo grupo, a ser realizada pelo INCRA - Instituto Nacional de Colonização e Reforma Agrária, a partir da consideração de práticas de territorialidade construídas pela comunidade e por ela afirmadas:

Art. $2 .^{\circ} \S 3 .^{\circ}$ Para a medição e demarcação das terras, serão levados em consideração critérios de territorialidade indicados pelos remanescentes das comunidades dos quilombos, sendo facultado à comunidade interessada apresentar as peças técnicas para a instrução procedimental. (Decreto n. $^{\circ} 4.887$, de 20 de novembro de 2003)

Retomando o parágrafo $2 .^{\circ}$ deste Artigo, a Instrução Normativa n. ${ }^{\circ} 16$, de 24 de março de 2004 atualizada pela Instrução Normativa $n .^{\circ} 20$, de 19 de setembro de 2005 , elaborada pelo INCRA para regulamentar os procedimentos de demarcação e titulação das terras quilombolas, aprofunda a definição destas terras "de direito":

Art. $4 .^{\circ}$ Consideram-se terras ocupadas por remanescentes das comunidades de quilombos toda a terra utilizada para a garantia de 
sua reprodução física, social, econômica e cultural, bem como as áreas detentoras de recursos ambientais necessários à preservação dos seus costumes, tradições, cultura e lazer, englobando os espaços de moradia e, inclusive, os espaços destinados aos cultos religiosos e os sitios que contenham reminiscências históricas dos antigos quilombos. (Instrução Normativa n. ${ }^{\circ} 20$, de 19 de setembro de 2005)

As terras de direito dos quilombolas passam a ser consideradas, então, todas aquelas ocupadas pela comunidade e também aquelas necessárias à preservação de seus costumes, tradições, cultura e lazer. Daqui, subentende-se que a definição do território quilombola se dá a partir das necessidades apontadas pela comunidade para a garantia de sua reprodução. $\mathrm{Na}$ identificação do território, a indicação dos critérios de territorialidade sustenta tanto o território ancestral, expropriado, quanto o território a ser reconstruído. Assim, a memória do parentesco em relação aos ancestrais e de outras relações delimita o território ancestral, da mesma maneira que confere direitos de sua reapropriação pelos descendentes atuais, transformandoo em patrimônio. Ou seja, o território quilombola é o território pleiteado. Como a identidade quilombola se afirma a partir da ancestralidade comum, o território pleiteado se baseia naquele vivido e guardado na memória. Neste sentido, configura o território dos véios, cujas referências no espaço são dadas, principalmente, pelos antigos locais de morada.

Analisando a dimensão do parentesco como princípio organizatório da reprodução social do campesinato, Ellen Woortmann o enfatiza como fundamento da identidade e das representações coletivas, bem como da reprodução do patrimônio através das gerações: "o parentesco, como ideologia e como prática, fornece uma resposta associada ao princípio territorial". (WOORTMANN, 1995:57)

Neste sentido, as relações de parentesco atuais e pretéritas efetivam a sustentação aos territórios quilombolas e projetam seu vir-a-ser. A expectativa pelo constructo territorial que garanta a reprodução das famílias enfatiza o caráter de patrimônio da terra e ordena o trabalho de identificação das comunidades quilombolas:

Para além da garantia da sobrevivência no presente, as relações no interior da família camponesa têm como referência o horizonte das gerações, isto $e ́$, um projeto para o futuro. Com efeito, um dos eixos centrais da associação camponesa entre família, produção e trabalho é a expectativa de que todo investimento em recursos materiais e de trabalho despendido na unidade de produção pela geração atual possa vir a ser transmitido à geração seguinte, garantindo a essa as condições de sua sobrevivência. (WANDERLEY, 1999:29)

A garantia de transmissão deste patrimônio às gerações seguintes é construída nas comunidades quilombolas pela titulação coletiva das terras, em nome de sua 
Associação. A titulação coletiva retira a terra do mercado, indo ao encontro da tradição camponesa onde "a terra não pode ser vendida a estranhos; ela não é uma mercadoria plena. De fato, ela não o é em nenhuma forma camponesa plena: ela é patrimônio da família ou da comunidade". (WOORTMAN, E., 1995:57)

$\mathrm{O}$ território pleiteado é o patrimônio que se quer transmitir às gerações. Ao iniciar seu processo de reconhecimento enquanto quilombola, a comunidade inicia, também, todo um trabalho educativo que visa assegurar a transmissão do territóriopatrimônio aos descendentes do ancestral comum. Assim, elaboram-se estratégias de reprodução da comunidade e de seu próprio território, que visam perpetuá-lo enquanto patrimônio. A partir de Marx, Pierre Bourdieu teoriza que o patrimônio se apropria do seu proprietário, ou seja, se a terra é do proprietário, o proprietário se faz da terra-patrimônio:

L'institutuion de l'héritier, qui, comme tout acte d'institution, ressortit à la logique de la magie, ne trouve sa pleine realization que par la vertu de $l$ incorporation: si, comme dit Marx, le patrimoine s'approprie son propriétaire, si la terre hérite (ou l'entreprise) faite homme, faite coros, incarnée sous la forme d'une structure génératrice de pratiques conformes à l'impératif fondamental de la pperpétuation de l'integrité du patrimoine. (BOURDIEU, 1980:257).

Enquanto proprietário do patrimônio de um conjunto que engloba os mortos, os vivos e os que virão a nascer (WOORTMANN, K., 1990:62), o indivíduo passa a desempenhar a tarefa de seu guardião, definida pela comunidade familiar. Nas sociedades camponesas, as estratégias de reprodução buscam evitar a fragmentação da terra-território-patrimônio, que constituem ameaça à continuidade de sua existência:

As práticas de herança (no seu sentido amplo) visam, principalmente, evitar a excessiva fragmentação das pequenas propriedades, que ameaça a reprodução desse campesinato. Os mecanismos que asseguram a manutenção da estrutura social camponesa têm como base a tradição, ou melhor, o 'direito costumeiro', que permite excluir da herança da terra um ou mais membros da familia. (SEYFERTH, 1985:1)

No entanto, em se tratando de comunidades quilombolas, a garantia do território se dá por meio da titulação coletiva das terras, conforme definido pelo INCRA:

Art. 23. Concluída a demarcação, a Superintendência Regional realizará a titulação mediante outorga de título coletivo e pró-indiviso às comunidades, em nome de suas associações legalmente constituidas, sem qualquer ônus financeiro, com obrigatória inserção de cláusula de 
inalienabilidade, imprescritibilidade e de impenhorabilidade, devidamente registrado no Serviço Registral da Comarca de localização das áreas. (Instrução Normativa n. ${ }^{\circ} 20$ de 19 de setembro de 2005)

Com base na titulação coletiva e indivisível da terra, não há possibilidade de definição de um herdeiro. Assim, a estratégia considerada como traço de campesinidade, no contexto atual das comunidades quilombolas não se sustenta, $\mathrm{e}$ a ela se sobrepõe a lógica do coletivo patrimonial. Por outro lado, há congruência na relação com a terra enquanto espaço de reprodução da vida, e não enquanto mercadoria, afirmada pela cláusula de inalienabilidade, imprescritibilidade e de impenhorabilidade das terras tituladas em nome das associações comunitárias quilombolas, conforme aponta Ellen Woortmann: Na comunidade fechada, mostra ainda Wolf, a terra não pode ser vendida a estranhos; ela não é uma mercadoria plena. De fato, ela não o é em nenhuma forma camponesa plena: ela é patrimônio da família ou da comunidade. (WOORTMANN, E., 1995:57) O momento atual reafirma, então, traços da campesinidade quilombola no Norte do Espírito Santo. O parentesco como sustentação do território; a consideração da terra como patrimônio, acompanhada da preocupação pela sua transmissão às gerações seguintes, com o intuito de garantir a reprodução social e identitária das famílias; e a dimensão política do processo de titulação das terras quilombolas reforçada pelo trabalho da Via Campesina - são algumas das características em evidência neste processo.

Aqui cabe analisar em que medida os traços da campesinidade afirmam o território quilombola, e de forma complementar, como o território e as práticas de territorialidade reforçam estes traços. Ao se pensar a respeito da sustentação deste território, cabe-se indagar sobre quais bases econômicas ela se dará. O objetivo da demarcação do território quilombola é assegurar a posse da terra como meio de produção fundamental, um lugar de vida e trabalho, capaz de guardar a memória da família e de reproduzi-la para as gerações posteriores. (WANDERLEY, 1999:44) No entanto, é necessário assinalar que em relação ao território de origem, a demarcação do território atual sempre vai significar uma (de)limitação. Em tempos pretéritos, onde a terra era à rola, este campesinato negro se reproduzia em seu modo de vida intrinsecamente vinculado à dinâmica natural do meio e à fertilidade natural do solo, sendo relativamente favorecido pela disponibilidade de terras.

Embora seja muito relevante a questão da autonomia relativa do campesinato, decorrente do controle sobre os meios de produção, e sobre o processo de trabalho (WOORTMANN, 1995:46), que le permite determinar por sí mismo el tiempo y la intensidad de su trabajo (CHAYANOV, [1925]1974:33), faz-se necessário considerar a limitação da disponibilidade de terras no território demarcado, o que também implica na limitação da capacidade produtiva agrícola e do uso de técnicas consideradas "tradicionais", como o rodízio, o pousio e a solta do gado e dos porcos. 
No mesmo sentido, é mister analisar a relação estabelecida com o mercado. Embora não produza exclusivamente para o mercado, historicamente o campesinato sempre esteve vinculado a ele, lugar das trocas entre o excedente produzido e outros produtos considerados necessários a sua reprodução social. A maior ou menor dependência em relação ao mercado pode contribuir na análise da campesinidade, onde devem ser consideradas as motivações desses produtores na luta pelo acesso a determinados recursos e serviços, a bens simbólicos e culturais. (NEVES, 1995:24) A vinculação ao mercado apresenta variadas formas e nuances, e não deve ser simplificada como processo de transformação do camponês em capitalista.

$\mathrm{Na}$ análise das comunidades quilombolas do Norte do Espírito Santo e a questão da sua sustentação, cabe abordar as alternativas que ora se lhes apresentam, oriundas da sociedade dominante, ora são pensadas por eles próprios para garantir a reprodução de suas vidas e a apropriação efetiva de seu território. Em meio a inúmeras dificuldades, estes movimentos podem se constituir em processos de campesinização, descampesinização e recampesinização. (WANDERLEY, 1999:41).

Neste sentido, propostas de alternatividade e autonomia camponesa constituem a proposição de se construir uma nova realidade social no campo. Para esta empreitada é fundamental o trabalho no campo das representações, onde o discurso proferido pelo campesinato e sobre ele deve ser capaz de o constituer en sujet de sa propre vérité. (BOURDIEU, 1977)

\section{CAMPESINIDADE E TERRITORIALIDADE QUILOMBOLANO NORTE DO ESPÍRITO SANTO}

Resumo: Este trabalho busca analisar as comunidades negras rurais do norte do Espírito Santo a partir das características e práticas camponesas na reapropriação de seu território. Estas práticas de territorialidade retomam antigas origens e saberes, e vêm sendo fortalecidas pela incorporação do direito étnico ao território, ora afirmado pelo Estado por meio de seu reconhecimento como "comunidades remanescentes de quilombos".

Palavras-chave: campesinato negro, quilombo, território.

\section{QUILOMBOLA “PEASANTINESS” AND TERRITORIALITY IN NORTH ESPÍRITO SANTO}

Abstract: This work aims to analyse the rural black communities of north Espírito Santo state, in Brazil, from the peasants characteristics and practices in the reappropriation of their territory. These practices of territoriality retake old origins and wisdoms, and they are being stressed through the incorporation of ethnic rights to territory, at the same time legitimated by the State through its recognition as "communities remaining of quilombos".

Keywords: black peasant, "quilombo", territory. 


\section{BIBLIOGRAFIA}

ALMEIDA, A. W. B. de. 1989. Terras de preto, terras de santo e terras de índio uso comum e conflito. In: Cadernos NAEA n ${ }^{\circ} 10$. Belém: UFPA/ NAEA.

BECKER, B. K. 1973. O Norte do Espírito Santo - região periférica em transformação. In: Revista Brasileira de Geografia n. 35 (4). Rio de Janeiro.

BOURDIEU, P. 1994. Stratégies de reproduction et modes de domination. Actes de la recherche en Sciences Sociales 105. Paris.

1980. La terre et les stratégies matrimoniales. In: Le sens pratique. Paris: Les Editions de Minuit.

1977. Une classe objet. Actes de la recherche en Sciences Sociales

17-18. Paris.

CÂNDIDO, A. 1988. Os parceiros do Rio Bonito (8.ed.). São Paulo: Livraria Duas Cidades.

CHAYANOV, A. V. 1974 (1924) La organización da la unidad económica campesina (2.ed.). Buenos Aires: Ediciones Nueva Visión.

CONTRERAS, J. 1991. Los grupos domésticos: estratégias de producción y reproducción. In: PRAT, J., MARTINEZ, U., CONTRERAS, J. e MORENO, I. (eds.) Antropología de los pueblos de España. Madrid: Taurus Universitaria.

FERREIRA, S. R. B. 2002. Da fartura à escassez: a agroindústria de celulose e o fim dos territórios comunais no Extremo Norte do Espírito Santo. Dissertação de Mestrado em Geografia Humana. São Paulo: USP.

GARCIA Jr., A. R. 1983. Terra de trabalho. Rio de Janeiro: Paz e Terra.

GOLDENSTEIN, L. 1975. Aspectos da reorganização do espaço brasileiro face a novas relações de intercâmbio - uma análise geográfica do reflorestamento e da utilização da madeira por indústrias de celulose. Tese de Livre-Docência em Geografia Humana. São Paulo: USP.

GONÇALVES, C. W. P. 2001. Da Geografia às Geo-grafias: um mundo em busca de novas territorialidades. Grupo de Trabajo de Economia Internacional. CLACSO - II Conferência Latinoamericana de Ciencias Sociales. Universidad de Guadalajara, México. (mimeo)

GUSMÃO, N. M. 1995. Caminhos Transversos: Território e Cidadania Negra. In: O'DWYER, Eliane C. (org.) Terra de Quilombos. Rio de Janeiro: ABA. HAESBAERT, R. 2004. O mito da desterritorialização: do "fim dos territórios" à multiterritorialidade. Rio de Janeiro: Bertrand Brasil.

MAGALDI, S. 1991. Ação do Estado e do grande capital na reestruturação da atividade econômica: o cultivo florestal e a cadeia madeiracelulosel papel. Dissertação de Mestrado em Geografia Humana. São Paulo: USP. 
NEVES, D. P. 1995. Agricultura familiar: questões metodológicas. Reforma Agrária vol. 25 (2-3). O'DWYER, E. C. (org.) 2002. Quilombos: identidade étnica e territorialidade. Rio de Janeiro: Fundação Getúlio Vargas.

OLIVEIRA, A. U. de. 1999. A Geografia Agrária e as transformações territoriais recentes no campo brasileiro. In: CARLOS, A.F.A. (org.) Novos caminhos da Geografia. São Paulo: Contexto.

1991. Integrar para não entregar: políticas públicas e Amazônia. São Paulo: Papirus.

QUEIROZ, M. I. P. de. 1973. O Campesinato Brasileiro - ensaios sobre civilização e grupos rústicos no Brasil (2.ed.). Petrópolis: Vozes.

REDFIELD, R. 1956. The peasant view of the good life. In: REDFIELD, R. Peasant society and culture. Chicago: The University of Chicago Press.

REIS, J. J. e GOMES, F. S. (orgs.) 1996. Liberdade por um fio - História dos quilombos no Brasil. São Paulo: Cia. Das Letras.

SEYFERTH, G. 1985. Herança e estrutura familiar camponesa. Boletim do Museu Nacional 52. Rio de Janeiro.

SHANIN, T. 1980. A definição de camponês: conceituações e desconceituações o velho e o novo em uma discussão marxista. Estudos CEBRAP 26.

WANDERLEY, M. N. B. 1999. Raízes históricas do campesinato brasileiro. In: TEDESCO, J.C. (org.) Agricultura familiar: realidades e perspectivas. Passo Fundo: EDIUPF.

2003. Agricultura familiar e campesinato: rupturas e continuidade. Estudos Sociedade e Agricultura 21. Rio de Janeiro: CPDA-UFRRJ.

WOORTMANN, E. F. 1995. Herdeiros, parentes e compadres. São Paulo-Brasília: Hucitec-EdunB

WOORTMANN, K. 1990. 'Com parente não se neguceia': o campesinato como ordem moral. Anuário Antropológico 87. Brasília: Ed. UnB- Tempo Brasileiro.

WOORTMANN, E. e WOORTMANN, K. 1997. O trabalho da terra - a lógica e a simbólica da lavoura camponesa. Brasília: Ed. UnB. 